\title{
A CASE OF ACANTHOSIS NIGRICANS.
}

BY

MALCOLM MORRIS, F.R.C.S.ED.

Received May 28th-Read June 12th, 1894.

THE following case is an example of one of the rarest of skin diseases, and is, as far as I am aware, the first of the kind reported in this country. The patient, who was sent to me by Dr. Mackern, of Blackheath, is a single woman æt. 35, and was admitted into St. Mary's Hospital under my care on February 15th, 1894. The notes have been condensed from the report made by my clinical assistant, Mr. Randolph Grosvenor. There is nothing in the patient's family history that would seem to have any bearing on her present condition. She says she had typhus and scarlet fever in childhood; otherwise her health was satisfactory up to the time she was attacked by the disorder from which she is now suffering. For more than a year before that, however, her menstrual history shows great irregularity. In the autumn of 1892 she began to suffer from menorrhagia. This continued for nearly a year, after which the periods, while continuing to be unduly frequent (once a week), were scanty in amount. Since April, 1893, she has suffered from leucorrhœa. About August, 1892, her hair, which had preVOL. LXXVII. 
viously been thick and long, became dry and wiry, and began to fall out. She had always been subject to dryness of the hands and feet, but her skin generally was soft in texture before the beginning of the present condition. There seems to have been no marked tendency to the formation of warts. About five years ago there were three warts on one of her thumbs, but these had disappeared before she came under observation. One pedunculated wart had, however, been present in each axilla for several years. She has always been of an excitable temperament, and the neurotic element in her constitution has become much more pronounced during the development of the skin affection.

The first appearance of the lesions dates from some eight months back. In the beginning of October, 1893, she noticed a general bronzing of the skin over the upper half of her body. About the same time crops of warts came out on the backs of her hands, the nails became uneven, and the skin between the fingers rough. Patches of skin on the chest, sides, and to a less extent on the back, became harsh and blackish. In the axillm the harshness soon passed into a wart-like thickening, the hypertrophied skin being quite black. At the end of December the skin on the palms and flexor surfaces of the fingers became thickened, and of an orange-yellow colour, and fissures formed on the finger ends. At the beginning of February the warty condition of the axillæ had greatly increased, and deep cracks had formed in the hypertrophic mass, from which a discharge exuded.

In the first week of January she noticed that her underclothing was stuck to her abdomen by a thick discharge; the source of this was found to be the umbilicus, which looked red in the middle. A week later the patient noticed a growth in that situation, which increased in size somewhat rapidly for two or three weeks, and then seemed to come to a standstill. The discharge was purulent in character, and was particularly abundant on movement. 
The first sign of involvement of the mucous membranes appears to have been a peculiar dryness of the lips, which the patient first noticed at the beginning of December, 1893. In the middle of January "lumps" formed on the tongue, and a few days later the mucous membranes on the inside of the cheeks became rough and wrinkled. At the end of the same month warts were observed on the roof of the mouth. Shortly before the patient's admission she noticed that the inside of her ears felt moist, and emitted a disagreeable smell, but there was no actual discharge; there was also some impairment of hearing. The condition became steadily worse up to the time of her admission, fresh crops of warts appearing in various parts of the body, the black patches increasing in size, and the bronzing becoming more diffused.

Condition on admission.- The patient looks wasted and her muscles are flabby, but her general health is fairly good. The temperature is normal. She is nervous but not hysterical; the knee-jerk is almost entirely absent on both sides.

Skin: The skin lesions present three principal features: 1st, diffuse brownish discoloration or bronzing; 2nd, patches of inky blackness; 3rd, warty growths. It will be most convenient to describe the appearances as seen on examining the patient from the head downwards. The skin of the whole upper part of the body is distinctly bronzed. The face looks slightly swollen and flushed, the redness deepening when she is spoken to. The skin of the face is dry and scurfy, and there are small warts on the skin and forehead, chin and cheek. The meatus auditorius on either side is packed with warts which obstruct the passage. The skin of the neck both in front and behind, and on the under surface of the chin, is coarse in appearance and stained black all round; at the back of the neck the discoloration extends upwards for a short way on the scalp, and in front it runs downwards from the neck in two narrow strips on either side of the middle line to the chest. The whole of the skin of the 
neck is rough and the natural folds are exaggerated. The roughness extends over the front of the chest, sparing the breasts except the left, which is very slightly affected; on the right mamma the skin is normal, but is dotted here and there with a few small warts. Both nipples are slightly discoloured and warty. Between the breasts the skin is coarse and blackened; on the sides of the chest it is fairly normal, with the exception of a small discoloured area immediately below the axillæ. In the axilla on each side the disease is seen at its highest degree of development. The whole of the space is occupied by black masses of warty growths separated by deep furrows, from which oozes a small quantity of offensive discharge. At one time the whole of the hypertrophied mass was quite black, but at present there is in the middle of each axilla a raw-looking patch of a bright fleshcolour. On the upper limbs the skin, except at the bend of the elbow, is normal down to the lower third of the forearm, but a number of small warts are scattered about, especially at the flexor surfaces. At the bend of the elbow there is a deep brown stain dotted with black spots. The natural folds of the skin are exaggerated. On the extensor surfaces nothing but slight roughness is observed. The palms of the hands and the flexor surfaces of the fingers are greatly thickened and show very marked deepening of the natural lines. The whole of the skin in these situations is of a light orange-colour, and feels like rough piled velvet. The backs of the hands as low as the knuckles and the backs of the wrists are fairly normal though rough, but at the edges and on the backs of the fingers the condition of the skin approximates to that of the palms.

Over the whole of the abdomen the skin is bronzed, rough, and wrinkled. In the middle line in front, a black band continuous with that between the breasts spreads downwards for some inches. In the situation of the umbilicus there is a button-like growth of considerable size, clearly papillomatous in nature. It is circular 
in shape, measuring $1 \frac{1}{2}$ inches across and about $\frac{1}{2}$ inch from above downwards; it is slightly narrowed at its attachment to the surrounding skin, and is surrounded by a blackened zone one inch in width. From about three inches below the umbilicus to the groins the skin presents no anomaly beyond slight general bronzing. On the fronts and inner aspects of the thighs the skin is natural, but in the latter situation a few small warts are scattered about. Behind towards the gluteo-femoral fold there is thickening with brown discoloration. Over the patellæ and behind the knees the skin is also thickened and generally discoloured, with here and there patches of blacker staining, especially in the popliteal spaces. From the knees down to the ankle the skin is dry and wrinkled, but otherwise normal. About the ankles in front and behind there is some discoloration and creasing. The feet are normal on the dorsal aspects, but on the sides and the soles the skin is dry, rough, and furrowed; the skin of the heel and of those parts of the foot which touch the ground in walking is very rough and thick, and of a yellow-brown colour. The skin on the ends of the toes is also very rough and thickened, and the nails are pushed some way out of their beds by a mass of horny tissue.

Mucous membranes.-Nearly all the visible mucous membranes are affected. The lips are swollen, dry, and of a pale orange-colour. The soft palate is covered with masses of small warty growths; and a similar condition is seen on the anterior portion of the hard palate on either side, on the cheeks, on the tongue, and on the gums. The throat is unaffected. The mucous lining of the vagina is covered with growths of similar appearance. The patient suffers from leucorrhœa, but the vaginal discharge appears to have been noticed some time before the onset of the skin affection.

It will thus be seen that the principal objective features of this remarkable disease are discoloration and wartiness of the skin. The distribution of the black stains is fairly symmetrical, and they show a marked predilection for 
the flexures and large natural folds of the integument (axillæ, bends of elbows, behind the knees, neck, between the breasts, \&c.). On close inspection the black patches are seen to be caused by numerous black granules. The individual granules as a rule are of about the size of a pin's head, but in the places where the stain is deepest (as in the axillæ) they are somewhat larger. They appear to be situated in the superficial layers of the epidermis, and can be readily brought to the surface by pinching up a fold of skin and rolling it between the fingers. The warty growths are simply papillomatous in structure as well as in appearance. There would seem to be no constant relation between them and the staining, for although the circumference of the warty masses in the axillæ is blackened as if by gunpowder, the warts on the face, arms, and mucous membranes show no trace of blackening. On the other hand, many of the black patches, as on the neck and in the bends of the elbows, though rough on the surface, are not warty.

Beyond the discomfort caused by the condition of the lips and mouth there are no subjective symptoms. The patient when first admitted complained of pain about the pubic region and the thighs, but this was probably connected with disordered menstruation.

The urine presents no abnormality.

While the patient has been under observation the black staining has spread over the entire surface of the abdomen and the whole of the back as high as the middle of the scapula. A few warts have developed on the scalp and in the lumbar region. About the middle of March it was noticed that a thick growth of white hair was taking place on the face, and to a less extent on the chest and abdomen. So luxuriant did the growth become on the face, invading the forehead and even the nose, that the patient asked to be allowed to shave. The hair on the head is rapidly turning grey, and is becoming very thin. On the other hand, there has been some improvement in other parts, especially the hands, feet, and knees ; in these 
situations there is less thickening and the skin is softer.

On March 15th the umbilical wart was removed; nothing but skin was involved in the growth. The warts in the auditory meatus were for some time treated by the application of salicylic acid, with the result that the hearing greatly improved. In other respects the treatment has been purely expectant.

I think there is no doubt that this case is an example of the disease to which Unna has given the name of Acanthosis nigricans, the substantive denoting a member

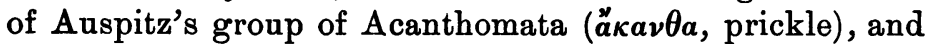
the adjective expressing the most striking feature of the affection. The symptomatology of the disease may be summed up as horny thickening with discoloration and wartiness of the skin. Only two cases have so far been recorded, one by S. Pollitzer ${ }^{1}$ and the other by V. Janovsky. ${ }^{2}$ Pollitzer's patient was a woman aged sixty-two, in whom the upper extremities, the neck, the mouth, part of the trunk, and the genito-crural regions were all attacked about the same time. The skin became discoloured ("dirty brownish"), rough, and covered in places with "diffuse warty prominences," the natural folds and furrows on the palm of the hand and elsewhere being strongly marked. The hard palate, tongue, and gums were covered with " fine granulations resembling small venereal warts, but softer to the touch." The patient recovered (apparently independently of the treatment pursued) in a few months as far as the condition of the skin was concerned, but soon died of anuria, which was believed by her medical advisers to be due to an internal cancer. No post-mortem examination was permitted. Microscopic sections of some of the warts showed hypertrophy of the Malpighian layer, the rete presenting, instead of the normal regular arrangement of its cells in rows or parallel layers, a confused

1 'Internat. Atlas f. Selten Hautkrankheiten.,' No. x.

2 Ibid., No. xi. 
appearance of whorls and gyri as if their atypical growth had proceeded concentrically from numerous points. There were frequent suggestions of "epithelial pearls." Careful search was made for micro-organisms, but none of a specific character were found.

Janovsky's patient was a man aged forty-two, who had for eighteen years been employed close to a furnace. The skin and mucous membranes were affected much in the same way as in Pollitzer's case. The umbilicus is described as standing out prominently in hemispherical form, darkly pigmented and papillomatous. The epiglottis and upper orifice of the larynx as well as the mouth and tongue were the seat of papillary outgrowths. The man's general health was unaffected.

Crocker has reported a case of "general bronzing without constitutional symptoms," " which presents considerable analogy with those of Pollitzer and Janovsky, but the mucous membranes and the hands were not involved, and there was no thickening of the horny layer to speak of. The affection arrived at its full development within a few days, and had remained practically unchanged for eight years. Crocker thinks it was probably an effect of exposure to extreme cold.

It should be noted that while in Pollitzer's case the tongue and mouth were painful from the beginning, and in Janovsky's there was severe itching, burning, and formication in the hands and other parts, in my patient such symptoms were entirely absent.

I have no suggestion to offer as to the ætiology or pathology of this curious affection; and, indeed, it would be absurd to attempt to erect any kind of theory, of however provisional a character, on so slender a basis of clinical facts. The only indication for treatment appears to be to keep the wart formation in check as far as possible by the use of the knife in the case of the larger growths, and by the application of salicylic acid to the smaller ones.

$$
1 \text { 'Clin. Soc. Trans.,' vol. xix (1881), p. } 152 .
$$


Histological report on Mr. Malcolm Morris's case of acanthosis nigricans, by J. Jackson Clarke, M.B.-The mushroom-like papillated growth at the umbilicus was attached by a pedicle of rough and harsh skin. The pedicle measured about two inches in circumference. After injecting 2 per cent. solution of cocaine the growth was removed. The skin was unusually resistent to the knife. Portions of the tissue were hardened in various media. All showed similar features, which may be expressed by the term papillomatous.

In detail the following changes may be noted :-Corium thicker than normal; the blood-vessels, veins especially, considerably dilated.

The papillary layer of the corium presented a dense small-cell infiltration at the level from which the papillm sprang.

The papillæ themselves were large, and contained many newly formed capillaries.

The subcutaneous tissue of the growth contained greatly dilated veins, but in other respects appeared to be normal.

The epidermis showed all the features of the normal epidermis with this modification, namely, that the horny layer was thicker than normal, and in some places shreds of this layer were partly detached.

The appendages showed no noteworthy change.

No black pigment was found in the tissues of the sections examined, but a closer examination revealed within the protoplasm scattered groups of cells of the rete, bright brown granules as if of hæmatoidin.

There were very few cells undergoing mitotic division present in the epidermis, and what mitoses there were presented quite regular forms.

The skin of the pedicle presented changes similar to but less marked than those described above.

A scraping from the darkest part of the rough skin on the front of the neck examined under the microscope showed- 
1. Epidermal scales, yellowish in colour, with hyphæ of fungi, spores, \&c.

2. Many black, opaque, angular and irregular particles.

3. A few brown translucent granules, resembling amorphous hæmatoidin.

After treating and scraping in succession with boiling caustic potash, hydrochloric acid, and ferrocyanide of potassium in solution, a faint blue colour was developed. Examined with the microscope the scraping now showed the angular particles to be unchanged; most of the brown masses had disappeared. Patches of blue were visible at separate points in the field, and were probably due to the reaction of iron previously contained in the brown masses with the ferrocyanide. Only one of the black particles was the seat of the blue reaction.

Thus it is probable that the brown masses were hæmatoidin from minute intra-epidermal hæmorrhages, and it is certain that the black particles were adventitious, chiefly coal, the one of them which gave a blue reaction having probably with it a particle of pyrites.

The epidermal scales appeared to be the seat of slight diffuse pigmentation, as they were rather yellower than normal.

(For report of the discussion on this paper, see 'Proceedings of the Royal Medical and Chirurgical Society,' Third Series, vol. vi, p. 129.) 
DESCRIPTION OF PLATES VI AND VII.

A Case of Acanthosis Nigricans (Malcolm Morris).

Plate VI.

Showing the symmetry of the eruption.

Piate VII.

1. Acanthosis nigricans of tongue and lip.

2. Acanthosis nigricans of bend of elbow. 
Plate VI

Med. Chir. Trans Vol. LXXVII.

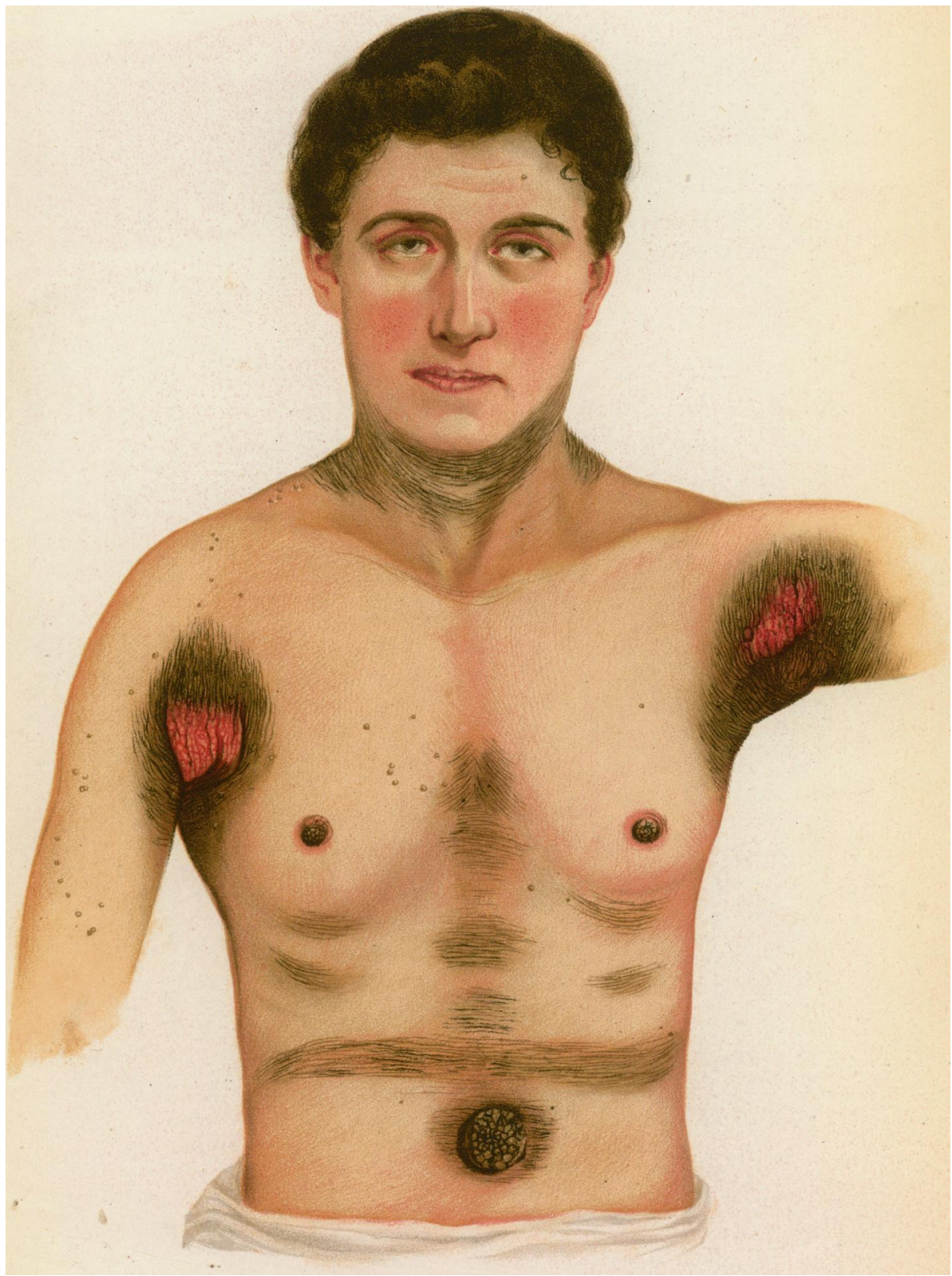


Plate VII.

Med. Chir. Trans Vol. LXXVII.

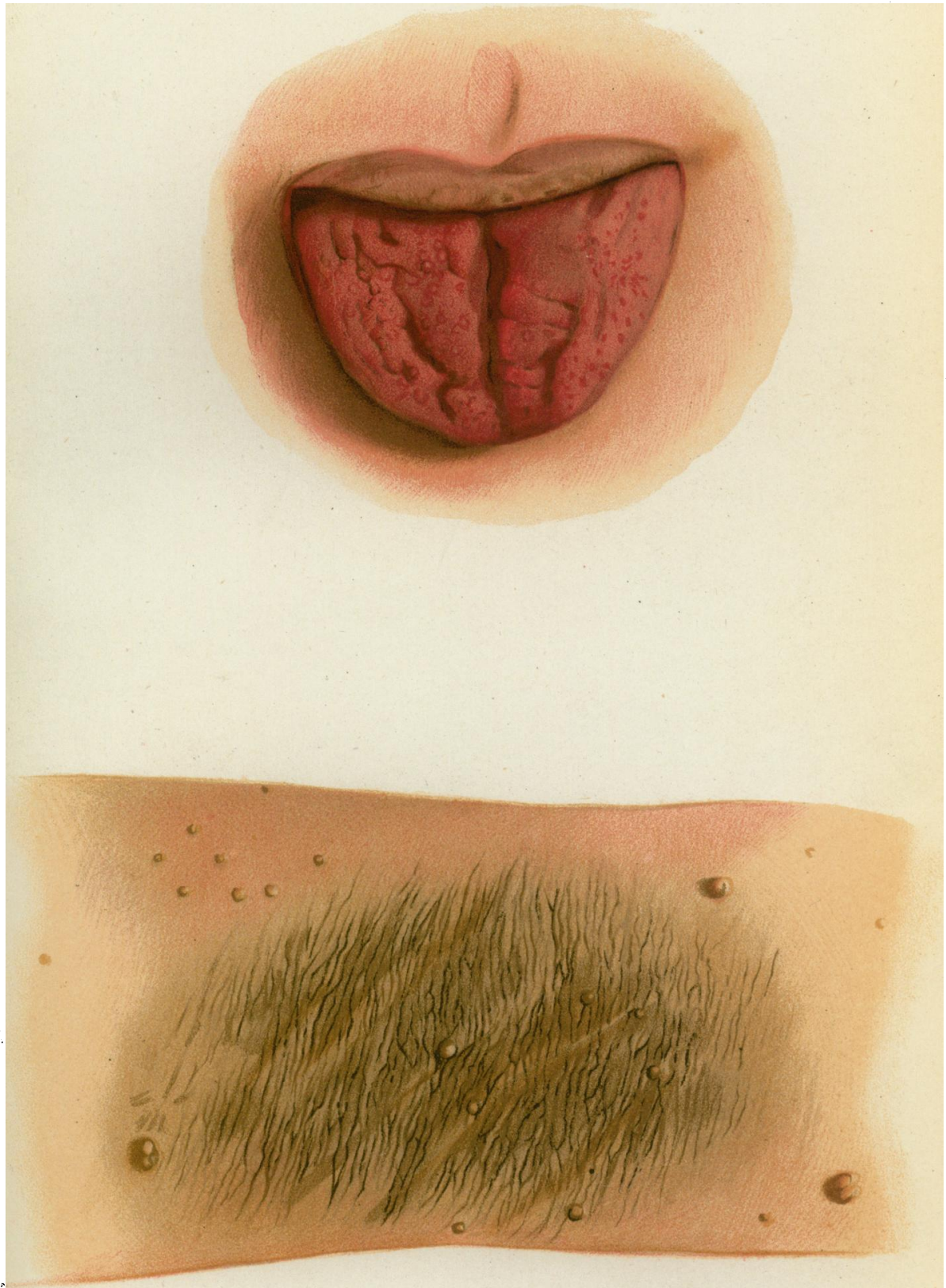

